\title{
Axon Guidance by Diffusible Chemoattractants: A Gradient of Netrin Protein in the Developing Spinal Cord
}

\author{
Timothy E. Kennedy, ${ }^{1,2}$ Hao Wang, ${ }^{1}$ Wallace Marshall, ${ }^{1}$ and Marc Tessier-Lavigne ${ }^{1,3}$ \\ ${ }^{1}$ Departments of Anatomy and Biochemistry and Biophysics, Howard Hughes Medical Institute, University of California, San Francisco, San Francisco, \\ California 94143, ${ }^{2}$ Departments of Neurology and Neurosurgery and Anatomy and Cell Biology, Center for Neuronal Survival, Montreal Neurological \\ Institute, McGill University, Montreal, Quebec, Canada H3A 2B4, and ${ }^{3}$ Division of Research, Genentech, South San Francisco, California 94080
}

Gradients of diffusible long-range attractant and repellent proteins have been proposed to guide growing axons during nervous system development, but such gradients have never been visualized directly. In the embryonic spinal cord, commissural axons pioneer a circumferential trajectory to the floor plate at the ventral midline directed by secreted proteins of the netrin family. In the embryonic chick spinal cord netrin-1 mRNA is expressed by floor plate cells and netrin-2 mRNA by neural epithelial cells. Antibodies to the two netrins reveal a gradient of netrin protein directly in the path of commissural axons. The netrin-1 gradient itself extends many cell diameters dorsal to the floor plate, the site of netrin-1 expression. A similar distribution of netrin-1 protein has been detected in embryonic rat and mouse spinal cord. The detection of a gradient of netrin-1 protein supports the operation of long-range chemotropic mechanisms in the developing nervous system.

Key words: chemotaxis; tropism; tropic; growth cone; commissure; diffusion

\section{Introduction}

The possibility that gradients of guidance cues might direct extending axons during neural development was proposed shortly after the discovery of the axonal growth cone (Ramón y Cajal, 1892). A gradient could be generated by differential expression of a nondiffusible short-range cue that remains associated with the cells that produce it, as is observed for the distribution of ephrins within the developing optic tectum (McLaughlin et al., 2003). Alternatively, diffusion of a secreted soluble cue away from its source of synthesis could, in principle, produce a gradient. Ramón y Cajal (1892) first proposed the existence of such chemotropic mechanisms, suggesting among others that the axons of commissural neurons within the embryonic spinal cord might reach the ventral midline by following a gradient of a cue secreted by the floor plate (Ramón y Cajal, 1899). In the century since this proposal the floor plate has been shown to secrete factors that can promote the outgrowth of commissural axons and reorient the direction of their growth (Tessier-Lavigne et al., 1988; Placzek et al., 1990; Kennedy et al., 1994; Serafini et al., 1994, 1996; Charron et al., 2003).

Netrin-1 and netrin-2 were purified from homogenates of

Received Dec. 6, 2005; revised July 19, 2006; accepted July 20, 2006

This work was supported by grants to M.T.-L. from the National Institutes of Health and the Howard Hughes Medical Institute and by grants to T.E.K. from the Canadian Institutes of Health Research, the Fonds de la Recherche en Santé du Québec, and Paralyzed Veterans of America Spinal Cord Research Foundation. We thank Konrad Beyreuther for suggesting the antigen enhancement protocol; Sasha Feynboym, Elena Malitskaya, and Erika Kennedy for technical assistance; and Christine Mirzayan and Lindsay Hinck for providing recombinant netrin protein.

Correspondence should be addressed to Marc Tessier-Lavigne, Genentech Incorporated, 1 DNA Way, South San Francisco, CA 94080. E-mail: marct|@gene.com.

DOI:10.1523/JNEUROSCI.5191-05.2006

Copyright $\odot 2006$ Society for Neuroscience $\quad$ 0270-6474/06/268866-09\$15.00/0 embryonic chick brain by using an in vitro assay designed to identify soluble cues that promote the outgrowth of commissural axons, mimicking the activity of the floor plate (Serafini et al., 1994). Recombinant netrin protein promotes commissural axon outgrowth, and a source of netrin reorients commissural axon extension within the embryonic neural epithelium over a distance of at least $250 \mu \mathrm{m}$ (Kennedy et al., 1994). Netrin mRNAs are expressed in the embryonic chick ventral spinal cord, with netrin-1 mRNA made by floor plate cells and netrin- 2 mRNA by neural epithelial cells in the ventral two-thirds of the spinal cord (excluding the floor plate), as the first commissural neurons extend axons toward the ventral midline (Kennedy et al., 1994).

Although guidance by diffusible chemoattractants now is widely accepted as a mechanism of axon guidance, no gradient of a diffusible chemoattractant protein has been visualized directly. Indeed, the absence of such evidence has been lamented (Dickson, 2002). Gradients of Sonic hedgehog (Shh) and Wingless type (Wnt) protein have been proposed to direct axon extension; however, only graded distributions of mRNA, not protein, expression have been reported (Lyuksyutova et al., 2003; Bourikas et al., 2005). In the case of netrins, although substantial evidence supports the proposal that netrin-1 acts as a chemotropic axon guidance cue, a previous immunohistochemical analysis actually reported the absence of a gradient of netrin protein in the embryonic spinal cord and the absence of netrin protein in the floor plate before the first commissural axons cross the ventral midline (MacLennan et al., 1997). In contrast, using more sensitive reagents and assays, we report detectable levels of netrin protein in the floor plate and neural epithelium as the first commissural neurons are being born, and we demonstrate the presence of a graded distribution of netrin protein directly in the path of extending commissural axons. These findings support the conclu- 
sion that netrin-1 functions as a long-range chemotropic axon guidance cue in the embryonic spinal cord.

\section{Materials and Methods}

Antibody production. The following peptide antigens were synthesized commercially for antibody production (Quality Controlled Biochemicals, Hopkinton, MA). Peptide 7872 (CN1), GYPGLLNMFAVQTAQPDPC, corresponding to the $19 \mathrm{~N}$-terminal amino acids of chick netrin-1; peptide 7871 (CN2), ANPFVAQQTPPDPC, corresponding to the 14 N-terminal amino acids of chick netrin-2; and peptide 11760 (pannetrin-2, PN2), RFNMELYKLSGRKSGGVC, and peptide 11991 (pannetrin-1, PN1), KPFHYDRPWQRATAREANEC, corresponding to sequences conserved in domain $\mathrm{V}$ of chick netrin-1 and chick netrin-2. Peptides were coupled to KLH (keyhole limpet hemocyanin) and polyclonal antisera raised in rabbits.

An antigen corresponding to domain VI and V of chick netrin-1 was generated by expression in Epstein-Barr virus nuclear antigen/human embryonic kidney 293 (EBNA 293) cells with the use of the pCEP4 vector (Invitrogen, Carlsbad, CA). Recombinant VI-V protein was collected in conditioned medium and purified in a single step by using a heparinSepharose high performance column (HR 5/10; Amersham Biosciences, Piscataway, NJ). Polyclonal sera against netrin VI-V were raised in rabbits (Babco, Richmond, CA).

For all sera, nonspecific antibody binding was preadsorbed with an acetone extract of adult chicken liver protein prepared as described (Harlow and Lane, 1988). Adult chicken liver does not express netrin-1 or netrin-2 (Kennedy et al., 1994), and preadsorption did not affect the affinity of the immune sera for recombinant netrin protein (data not shown). Specific antibodies were affinity-purified by using antigenlinked resin (sulfo-link or carbo-link; Pierce Biotechnology, Rockford, IL). After binding, the columns were washed with PBS, pH 7.5, antigenspecific antibodies were eluted with $3.5 \mathrm{M} \mathrm{MgCl}_{2}$, and then they were dialyzed extensively against PBS, pH 7.5. Recombinant myc epitopetagged chick netrin-1 and chick netrin-2 were produced and purified as described (Kennedy et al., 1994). The monoclonal antibody against neurofilament M, NFM (Lee et al., 1987), was provided by Dr. Virginia Lee (University of Pennsylvania, Philadelphia, PA).

Immunohistochemistry, antigen enhancement, and in situ hybridization. Chick embryos were staged according to Hamburger and Hamilton (1992). For immunohistochemical analysis the embryos were fixed in Carnoy's fixative (60\% ethanol, $10 \%$ acetic acid, $30 \%$ chloroform) for $2 \mathrm{~h}$ at room temperature. Embryos next were processed for embedding in paraffin (Harlow and Lane, 1988) with two changes of 100\% ethanol for $20 \mathrm{~min}$ and then were equilibrated with toluene for $1 \mathrm{~h}$ at room temperature, followed by paraffin for $2 \mathrm{~h}$ at $60^{\circ} \mathrm{C}$. The $6-8 \mu \mathrm{m}$ sections were cut and collected on Superfrost Plus slides (Fisher Scientific, Pittsburgh, PA). Paraffin was removed by immersion in xylene, and the sections were rehydrated by using a graded $\mathrm{EtOH} / \mathrm{H}_{2} \mathrm{O}$ series.

Protein-protein interactions in the extracellular matrix (ECM) often interfere with antibody-epitope interactions. Here, netrin antigenicity was enhanced by heating the sections in boiling sodium citrate buffer (Shi et al., 1991). Paraffin sections mounted on Superfrost Plus slides (Fisher Scientific) were submerged completely in $10 \mathrm{~mm}$ sodium citrate, $\mathrm{pH}$ 6.0, in a glass histology box. The buffer then was brought to a boil in a microwave oven, and the slides were boiled in buffer for $10 \mathrm{~min}$. Slides immersed in buffer were allowed to cool for $15 \mathrm{~min}$ and then washed twice for $5 \mathrm{~min}$ in PBS at room temperature. The supplemental Figure 1 (available at www.jneurosci.org as supplemental material) shows the effect of this treatment on netrin antigenicity on adjacent sections of stage 23 chick brachial cord (panel $A$ with antigen enhancement and panel $B$ without). Identical camera exposure times were used for each image. With the exception of the supplemental Figure $1 B$ (available at www. jneurosci.org as supplemental material), all of the immunohistochemical results that are presented used this antigen enhancement protocol. The effect of this treatment was equally dramatic for all netrin antibodies that were used, suggesting that netrin protein may be complexed with components of the ECM and that the enhancement is attributable to denaturation and disruption of protein-protein complexes, exposing reactive epitopes.
For immunohistochemical analyses the sections were blocked with Tris-buffered saline, $\mathrm{pH} 8.0,3 \%$ heat-inactivated normal goat serum, $5 \%$ dry milk, $1 \%$ glycine, and $0.1 \%$ Tween 20 . Incubation with primary antibody and all washes were performed in the presence of blocking solution. Immunoreactivity was visualized with secondary antibodies coupled to alkaline phosphatase (Invitrogen) or to the fluorophores cyanine 3 (Cy3) and Cy2 (Amersham Biosciences). Alkaline phosphatase activity was detected by using BM purple substrate (Roche Applied Science, Indianapolis, IN).

In situ hybridization was performed as described (Kennedy et al., 1994).

Quantification of the distribution of netrin protein. Immunohistochemical analysis was performed as described above. Fluorescence was quantified by using a cooled CCD camera as described (Swedlow et al., 1993). Cy3 fluorescence was captured by using a fixed $1 \mathrm{~s}$ exposure. Fluorescence was collected from square regions $6.92 \mu \mathrm{m}$ per side, a total area of $\sim 48 \mu \mathrm{m}^{2}$ (one pixel corresponds to a square $0.33 \mu \mathrm{m}$ per side; each data point integrated $21 \times 21$ pixels). The red Xs mark the trajectory of extending commissural axons and the center of each $48 \mu \mathrm{m}^{2}$ area digitally sampled. Beginning at the ventral midline of the floor plate and following the trajectory of extending commissural axons in both directions around the edge of the neural tube, we pooled the data into $20-\mu \mathrm{m}$ long bins. Data from five stage 17 sections and three stage 23 sections, both left and right sides, were pooled and analyzed. Error bars are the SEM.

Analysis of floor plate conditioned medium. Embryonic day 13 (E13) rat ventral embryonic spinal cord containing the floor plate was dissected and cultured on a substrate of poly-L-lysine and laminin- 1 for $2 \mathrm{~d}$ at $37^{\circ} \mathrm{C}$ in serum-free medium (OptiMEM, Glutamax I, 3.6\% D-glucose, penicillin/streptomycin; Invitrogen). Conditioned medium was collected, and protease inhibitors were added ( $1 \mathrm{~mm}$ PMSF, $1 \mathrm{~mm}$ EDTA, $1 \mu \mathrm{g} / \mathrm{ml}$ pepstatin A, $2 \mu \mathrm{g} / \mathrm{ml}$ aprotinin, $2 \mu \mathrm{g} / \mathrm{ml}$ leupeptin; Roche Applied Science). Cells and ventral spinal cord tissue attached to the substrate were extracted by using $1 \mathrm{ml}$ of buffered high salt solution $(1.5 \mathrm{M} \mathrm{NaCl}$, phosphate-buffered to $\mathrm{pH} 7.5$ with protease inhibitors as above) for 30 min at room temperature. Protein then was concentrated by TCA precipitation, the pellet was resuspended in $10 \mathrm{~mm}$ Tris, $\mathrm{pH}$ 7.4, plus protease inhibitors, and the protein concentration was quantified by using the BCA assay (Pierce Biotechnology). Then $60 \mu \mathrm{g}$ of protein was loaded per lane, separated by $10 \%$ PAGE, and electroblotted to polyvinylidene difluoride membrane (Fisher Scientific) for Western blot analysis.

\section{Results}

\section{Generation of antibodies specific to chick netrin-1 and netrin-2}

To test whether netrin protein diffuses from its site of synthesis in vivo, we first focused on the chick embryo because of the tight restriction of netrin-1 mRNA expression to the ventral midline in that species. Thus any netrin-1 protein observed at a distance from the chick midline would provide evidence for diffusion; in rodents, in contrast, netrin-1 transcripts are found outside the midline also (see below), making it more difficult to determine the site of origin of netrin-1 protein.

To visualize chick netrin- 1 and netrin-2 protein distributions individually, it was necessary to generate specific antibodies. The two chick netrin proteins show high sequence identity over their entire lengths, with only a small number of stretches of amino acids that differ between the two (Serafini et al., 1994). We therefore generated antibodies directed against specific peptides corresponding to unique sequences at the $\mathrm{N}$ termini of netrin- 1 and netrin-2 (peptides CN1 and CN2, respectively) (Fig. 1A). Polyclonal antibodies against these peptides were raised in rabbits. Nonspecific antibodies were removed from serum by preadsorption, and specific antibodies were purified additionally by using antigen-linked affinity columns (for details, see Materials and Methods), resulting in antibody $\mathrm{CN} 1$ against netrin-1 and antibody CN2 against netrin-2. Western blot analysis that used re- 

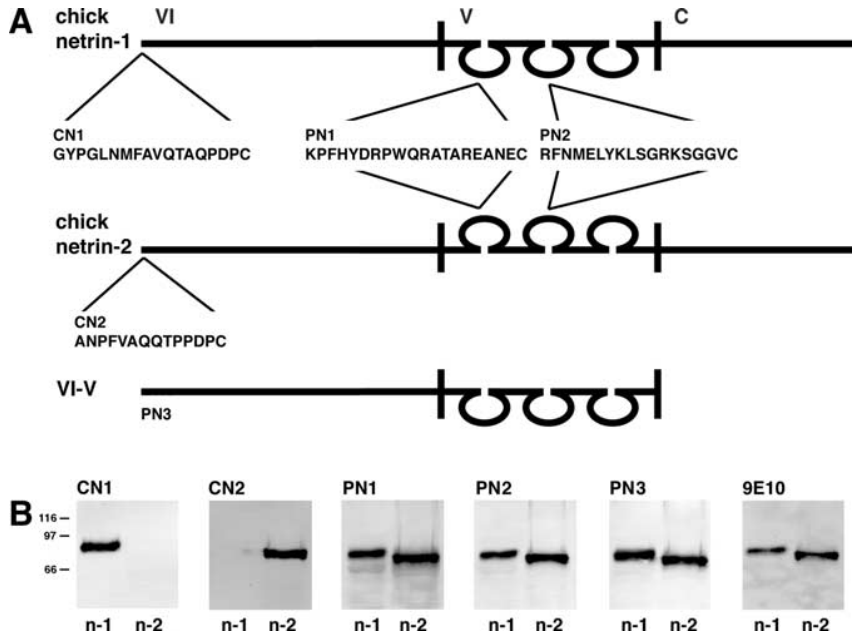

Figure 1. Specificity of netrin antibodies. A, Peptide antigens were synthesized that correspond to sequences derived from the mature $N$ terminus of chick netrin-1 (CN1) and chick netrin 2 (CN2). These sequences are unique to chick netrin-1 and chick netrin-2, respectively. Peptides also were synthesized that correspond to sequences within the domain V EGF-like loops (PN1, PN2) that are conserved in vertebrate netrin-1, netrin-2, and netrin-3 sequences. The PN1 peptide sequence is identical to the corresponding sequence of chick, rat, and mouse netrin-1 and contains a single conserved amino acid substitution in chick netrin-2. PN1 is poorly conserved in mouse netrin- 3 and netrin-4, containing six of 20 and 17 of 20 amino acid substitutions, respectively. The PN2 sequence is identical in netrin- 1 and netrin- 2 in chick, rat, and mouse netrin-1. Two conservative amino acid substitutions are present in mouse netrin-3, and the corresponding sequence in mouse netrin- 4 is poorly conserved, containing 10 of 18 amino acid substitutions. Recombinant chicken netrin-1 domain VI-V (PN3) is a 429 amino acid sequence that shares $\sim 90 \%$ amino acid identity with mouse netrin- $1, \sim 75 \%$ amino acid identify with chick netrin-2, $\sim 57 \%$ amino acid identity with mouse netrin-3, and $\sim 35 \%$ amino acid identity with mouse netrin-4. $\boldsymbol{B}$, Antibody specificity was assessed by using purified recombinant netrin protein and Western blot analysis. In total, $50 \mathrm{ng}$ of purified recombinant full-length myc-tagged chick netrin-1 (n-1) or chick netrin-2 (n-2) protein was loaded per lane. The 9E10 monoclonal antibody against a myc epitope tag confirmed that approximately the same amount of recombinant protein was loaded in each lane. Molecular weight markers, indicated with black bars on the left, correspond to 116,97 , and $66 \mathrm{kDa}$. Antibodies raised against peptide epitopes (CN1) and (CN2) are specific for chick netrin-1 and chick netrin-2, respectively. Antibodies raised against the conserved epitopes (PN2, PN3) recognize both recombinant chick netrin-1 and chick netrin-2.

combinant chick netrin-1 and chick netrin-2 protein confirmed that each of these two antibodies recognizes its specific antigen without any cross-reactivity with the other (Fig. $1 B$ ).

In addition, to obtain antibodies that recognize both proteins equally, we raised antibodies against two peptides corresponding to sequences that are conserved between the two proteins (PN1 and PN2) (Fig. 1A). Sera were also raised against purified recombinant domain VI and V of chick netrin-1, which shares $\sim 75 \%$ amino acid sequence identity with chick netrin-2 (PN3) (Fig. $1 A)$. Specific antibodies again were obtained by preadsorption and affinity purification. The resulting pan-netrin antibodies PN1, PN2, and PN3 each recognized equally well both recombinant chick netrin- 1 and netrin-2, as assessed by Western blotting (Fig. $1 B$ ) and by immunolabeling of transfected African green monkey kidney (COS) cells expressing netrin-1 or netrin-2 (data not shown). In addition, it is expected that PN1 and PN2 antibodies will bind both mouse and rat netrin-1, because the sequences against which they are directed are identical in mouse and rat netrin-1 (Serafini et al., 1996; Manitt et al., 2001). The sequences are conserved less highly in mouse and rat netrin-3; the stretch of amino acids corresponding to PN1 has six amino acid substitutions, and the stretch corresponding to PN2 has two. Nonetheless, antibodies PN1 and PN2 both recognize recombi- nant mouse netrin-3, as assessed by Western blotting (data not shown). In contrast, the corresponding regions of mouse netrin-4 and mouse netrin-G1 and netrin-G2 are poorly conserved and unlikely to be recognized by either PN1 or PN2 (Koch et al., 2000; Nakashiba et al., 2000, 2002; Yin et al., 2000). Preincubating the antibodies with either recombinant domain VI and $\mathrm{V}$ of netrin-1 or the corresponding peptide antigens blocked all staining (supplemental Fig. 2, available at www.jneurosci.org as supplemental material).

Netrins are related to laminins (Serafini et al., 1994). Western blot analysis that used purified mouse laminin-1 [EngelbrethHolm-Swarm cell laminin (EHS), Collaborative Biomedical Products/Becton Dickinson, Bedford, MA] or laminin-2 (merosin; gift from Dr. Lisa McKerracher, University of Montreal, Montreal, Quebec, Canada) revealed no cross-reactivity with netrin antibodies $\mathrm{CN} 1, \mathrm{CN} 2, \mathrm{PN} 1, \mathrm{PN} 2$, or PN3. Conversely, polyclonal antibodies raised against mouse laminin-1 (Collaborative Biomedical Products) did not recognize recombinant chick netrin-1 or chick netrin-2 but did bind mouse laminin-1 on Western blots (data not shown).

\section{Detection of netrin immunoreactivity in the developing chick spinal cord}

Netrin-1 and netrin-2 mRNAs are expressed in the embryonic chick spinal cord as commissural axons extend to the floor plate (Kennedy et al., 1994). To visualize the distribution of netrin protein and compare it with the pattern of netrin expression, we performed in situ hybridization and immunohistochemical analyses of comparable sections of embryonic chick brachial spinal cord. Only very limited netrin protein immunoreactivity was detected by using antibodies $\mathrm{CN1}-2$ or PN1-3 when the tissue was processed for immunohistochemistry by standard methods, including paraformaldehyde (PFA) fixation (data not shown), presumably because of the masking of the epitopes recognized by the antibodies. We found, however, that immunoreactivity could be detected readily by using a modification of an "antigen enhancement" procedure (Shi et al., 1991) in which the tissue was fixed by using an organic fixative and then exposed to boiling citrate buffer (for details, see Materials and Methods) (also see supplemental Fig. 1, available at www.jneurosci.org as supplemental material). This approach is thought to permit antibodies to detect epitopes that either are buried normally within the secondary structure of a protein or are masked by other interacting factors (e.g., for proteins like the netrins, possible binding partners in the ECM) by denaturing the proteins and exposing the epitopes. The immunoreactivity profiles described below were all detected by using this approach. We believe that these profiles accurately reflect the distribution of netrin protein, based on consistency with in situ hybridization patterns for the corresponding mRNAs (discussed below) and the fact that the distribution of immunoreactivity seen with the pan-netrin antibody PN2 appears to be the sum of the immunoreactivities seen with the two specific antibodies $\mathrm{CN} 1$ and $\mathrm{CN} 2$ (Fig. 2).

At stage 17, when the earliest commissural neurons were extending axons toward the floor plate, netrin-1 mRNA was restricted to the floor plate region (Fig. 2A) (Kennedy et al., 1994). In contrast, at this stage netrin-1 immunoreactivity was detected in the floor plate and the ventral neural epithelium, extending into the dorsal spinal cord (Fig. 2B). Interestingly, despite the restriction of netrin-1 mRNA to the floor plate, netrin-1 immunoreactivity was not enriched in floor plate and even appeared lower there when compared with the ventral two-thirds of the spinal cord (Fig. $2 B$ ). 

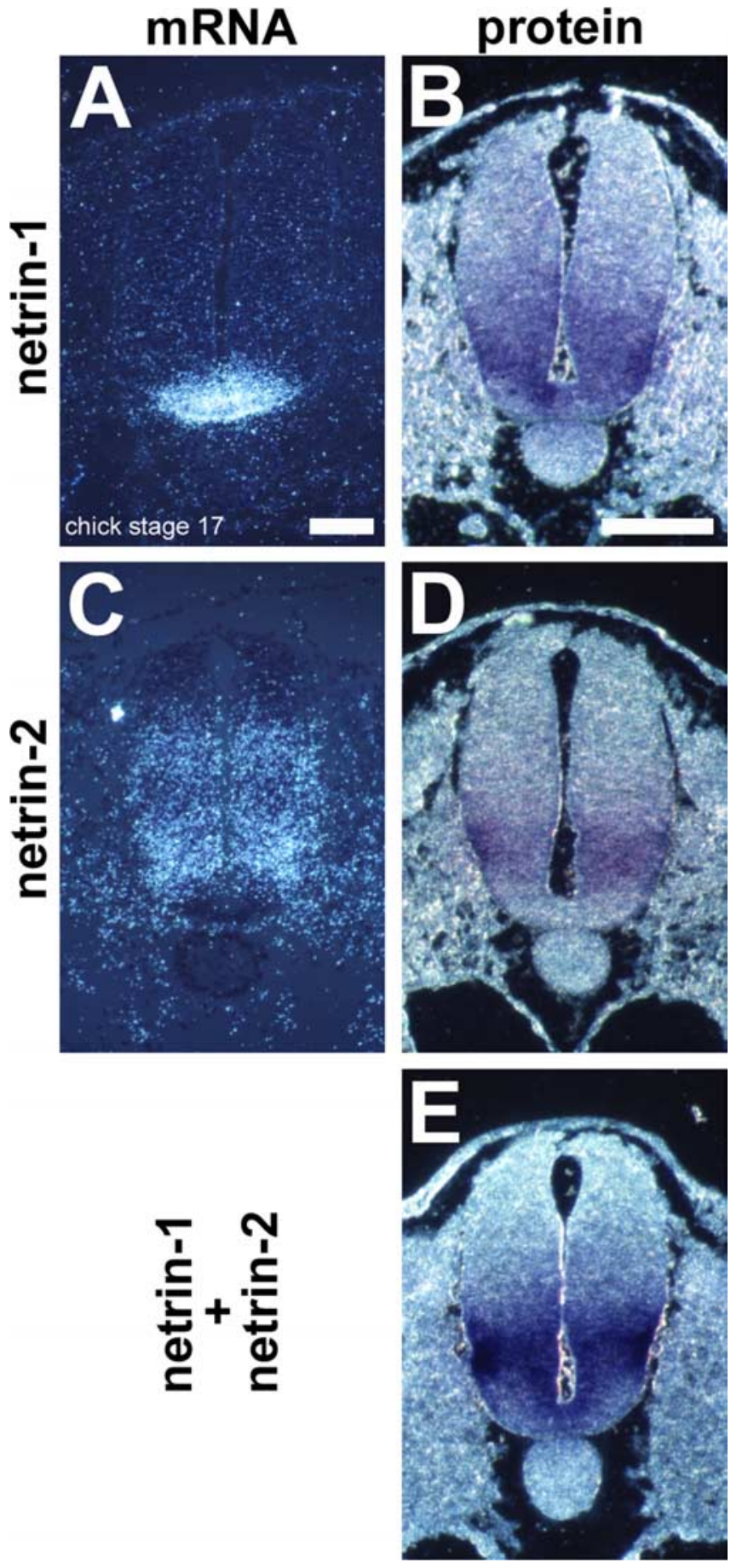

Figure 2. Distribution of netrin- 1 and netrin-2 mRNA and protein in stage 17 embryonic chick spinal cord. $\boldsymbol{A}$, In situ hybridization shows netrin-1 mRNA expression restricted to the floor plate region. $\boldsymbol{B}$, Netrin-1 protein, visualized with antibody CN1, was detected in the floor plate, throughout the ventral spinal cord, and into the dorsal spinal cord. C, In situ hybridization analysis indicates the absence of netrin- 2 mRNA from the floor plate but its presence in the ventral two-thirds of the spinal cord at stage 17. D, The netrin-2-specific antibody, CN2, reveals a distribution of protein similar to the distribution of netrin-2mRNA shown in C. E, Antibody PN2 reveals a distribution of total netrin protein like that of CN1 and CN2 combined. All sections are brachial stage 17 chick spinal cord. Immunoreactivity was visualized by using alkaline phosphatase-linked secondary antibody, BM purple substrate, and dark-field optics. Scale bars: $\boldsymbol{A}$ (for $\boldsymbol{A}, \boldsymbol{C}$ ), $\boldsymbol{B}$ (for $\boldsymbol{B}, \boldsymbol{D}, \boldsymbol{E}), 50 \mu \mathrm{m}$. Differences between the size of the sections prepared for in situ hybridization and for immunohistochemistry are attributable to the different fixation conditions that were used; the organic fixative used for immunohistochemistry dehydrates and shrinks the tissue relative to the aqueous PFA fixation used for in situ hybridization.
As previously described (Kennedy et al., 1994), netrin-2 expression was detected in the ventral two-thirds of the developing spinal neural epithelium, but not in the floor plate at stage 17 (Fig. 2C). The exposure time used to reveal netrin-2 transcripts was substantially longer than for netrin-1, consistent with previous findings that netrin- 2 mRNA is expressed in embryonic spinal cord at significantly lower levels than netrin-1 (Kennedy et al., 1994). The netrin-2-specific antibody CN2 revealed a distribution of netrin-2 protein (Fig. $2 D$ ) that appeared to correspond to the cells expressing netrin-2 mRNA (Fig. 2C), i.e., in the ventral two-thirds of the spinal cord, excluding the floor plate. It is interesting to note that, despite the almost complete non-overlap of netrin-1 and netrin-2 transcripts, the patterns of immunoreactivity of the two protein products show tremendous overlap in the ventral two-thirds of the spinal cord. The major difference in immunoreactivity patterns is the presence of some netrin-1 protein in the floor plate region, where netrin- 2 is absent.

Consistent with the distributions of netrin-1 and netrin-2 proteins revealed with specific antibodies, the pan-netrin antibody PN2, recognizing both netrin-1 and netrin-2, revealed a pattern of total netrin protein expression that appeared to be the sum of the individual patterns for netrin-1 and netrin-2 (Fig. 2E); expression in the floor plate, although visible, was low and enriched on the dorsal side of this structure. Expression in the ventral two-thirds was strong and strongest at the edges of the spinal cord (but within the gray matter proper). Between the ventral two-thirds and the floor plate there appeared to be a "gap," a region of reduced netrin immunoreactivity, discussed in greater detail below. A final confirmation that the pattern observed with PN2 was indeed netrin immunoreactivity was provided by the fact that a similar pattern was observed by using antibody PN1 raised against a peptide antigen (11991) different from that used to generate antibody PN2 (11760) (Fig 3H-J).

\section{Netrin protein distribution during commissural axon pathfinding}

To examine the distribution of netrin protein in relation to the trajectories of extending commissural axons, we performed double-labeled fluorescent immunohistochemistry by using the pan-netrin antibody PN2 (red) (Fig. 3) and the axonal marker NFM (green) (Fig. 3). The pattern of netrin protein expression visualized by fluorescence at stage 17 (Fig. $3 B$ ) matched that seen with an alkaline phosphatase reporter in Figure $2 E$, albeit with a lower signal-to-noise ratio. At this stage early commissural axons are extending to the midline (Fig. 3C). At stage 23, after a limited number of commissural axons have crossed the ventral midline, netrin protein continues to be detected in the floor plate (Fig. $3 D, E)$. Netrin immunoreactivity is associated closely with the path of commissural axons as they extend through the expanding pool of motor neurons in the ventral horn. Strikingly, as axons continue to cross and the nascent ventral commissure grows in size, the strongest netrin immunoreactivity in the spinal cord is associated closely with axons in the ventral commissure itself (stage 27) (Fig. 3F, G).

To appreciate the extent of netrin protein distribution at different ages, we show in Figure 3, $H-J$, cross sections through the embryonic chick spinal cord from three different ages (stages 15, 17 , and 34, respectively) at the same magnification. Using the pan-netrin antibody PN1, we see that, as the spinal cord grows in size, the relative area occupied by netrin protein within the spinal cord shrinks dramatically, becoming restricted to the ventral midline area. However, this "shrinkage" is relative, not absolute, 
because it is offset by the simultaneous dramatic increase in the size of the spinal cord; the net result is that the absolute area occupied by netrin immunoreactivity does not change markedly throughout this pe$\operatorname{riod}($ Fig $3 H-J)$.

\section{Additional evidence for a netrin gradient}

To characterize additionally the spatial distribution of netrin protein within the spinal cord, stage 27 chick spinal cords were microdissected into dorsal and ventral halves. Previous in situ hybridization analysis of stage 27 spinal cord indicated that netrin-1 continued to be expressed at a high level in the floor plate at that stage (Kennedy et al., 1994). The isolated dorsal and ventral portions of stage 27 spinal cords were homogenized, and equal amounts of dorsal and ventral protein extract were separated by PAGE for Western analysis. Pan-netrin antibody PN2 detected a single band of $\sim 78 \mathrm{kDa}$, consistent with the molecular weight of recombinant netrin protein (Kennedy et al., 1994). This band was strongly enriched in ventral spinal cord extract but also was present in dorsal spinal cord protein extract, albeit at a very low level (Fig. 4A), confirming a differential distribution of netrin protein along the dorsoventral axis of the embryonic spinal cord.

Floor plate cells express both cellassociated and diffusible forms of commissural axon outgrowth-promoting activity (Tessier-Lavigne et al., 1988; Serafini et al., 1996). Epitope-tagged recombinant netrin protein expressed by COS cells also partitions into a membrane-associated fraction that can be extracted with high salt and a soluble fraction present in conditioned medium (Kennedy et al., 1994; Serafini et al., 1994). The amount of chick netrin-1 protein present in the conditioned medium from transfected COS cells was $\sim 20 \%$ of that in the salt-extractable component and that of chick netrin- 2 was somewhat less (Kennedy et al., 1994). To determine the extent to which netrin-1 protein produced by the floor plate is freely soluble or membrane-bound, E13 rat ventral spinal cord explants containing the floor plate were dissected and cultured on a substrate of poly-L-lysine and laminin-1 in serum-free media for $2 \mathrm{~d}$. Conditioned medium then was collected, and the cells were attached to the substrate that was extracted by using $1.5 \mathrm{M} \mathrm{NaCl}$.

The total protein content of the extract and the conditioned medium was determined, and equal amounts of each were separated by PAGE. Western analysis with the use of antibody PN2 detected netrin protein in both the high salt extract of cultured ventral notochard.
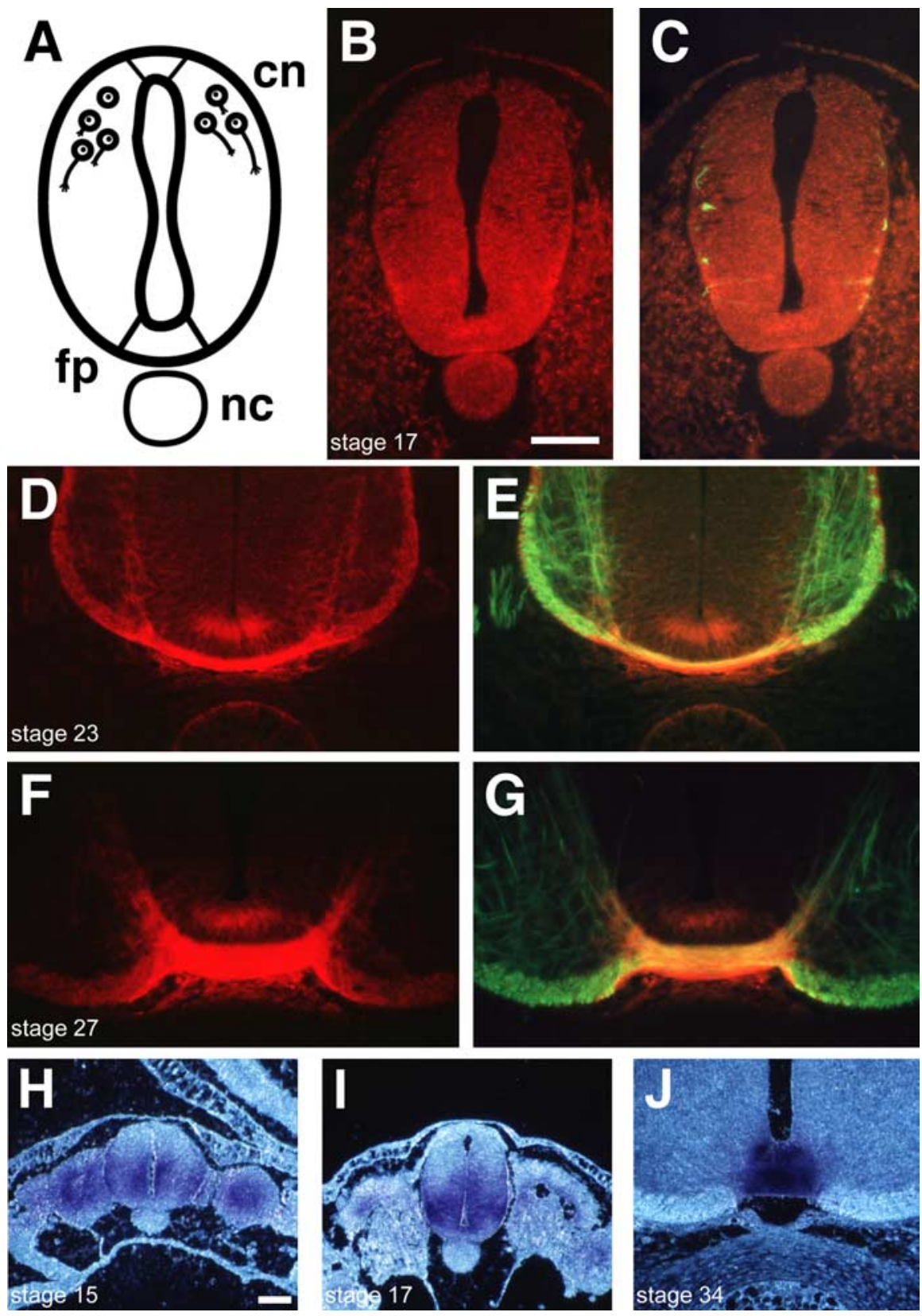

Figure 3. $\boldsymbol{A}-\boldsymbol{C}$, Distribution of netrin protein as commissural axons extend toward and cross the ventral midline in the chick. Shown is distribution of netrin (PN2 and red Cy3-conjugated secondary antibody) and the axonal marker neurofilament M (green (y2-conjugated secondary antibody) in the embryonic chick spinal cord. Netrin immunoreactivity is detected in the stage 17 floor plate ( $\mathrm{fp})$ and ventral neuroepithelium as commissural axons extend ipsilaterally. At stage $23(\boldsymbol{D}, \boldsymbol{E})$ after the first axons have crossed the ventral midline, netrin immunoreactivity is still present in the apical floor plate and ventral neuroepithelium but now also is concentrated in the ventral commissure itself. As the embryonic spinal cord matures (stage $27, \boldsymbol{F}, \boldsymbol{G}$ ), netrin is still detected in the floor plate and concentrated along the path of the commissural axons, particularly in the commissure itself. In C, E, G, NFM immunoreactivity also marks the axons of developing ventral horn motor neurons extending into the ventral roots. All images are presented at the same magnification, illustrating the relative size of the spinal cord at different developmental stages. All sections are brachial embryonic spinal cord. Scale bar: (in $\boldsymbol{B}) \boldsymbol{A}-\mathbf{G}, 50 \mu \mathrm{m}$. $\boldsymbol{H} \boldsymbol{J}$, The distribution of netrin immunoreactivity detected with the pan-netrin antibody PN1. $\boldsymbol{H}$ (stage 15) shows the distribution of protein before commissural neurons are born, $\boldsymbol{I}$ (stage 17 ) as commissural axons are extending toward the floor plate, and $\boldsymbol{J}$ (stage 34 ) after many axons have crossed to the contralateral side. Each panel was photographed at the same magnification and is presented at the same scale (alkaline phosphatase-coupled secondary antibody, visualized with BM purple and dark-field optics). Scale bar: (in $\boldsymbol{H}$ ) $\boldsymbol{H}-\boldsymbol{J}, 30 \mu \mathrm{m}$. Cn, Commissural neuron; nc,

spinal cord and in conditioned medium. Similar to the commissural axon outgrowth-promoting activity of the floor plate (Tessier-Lavigne et al., 1988; Serafini et al., 1994) and to recombinant netrin protein produced by COS cells (Kennedy et al., 

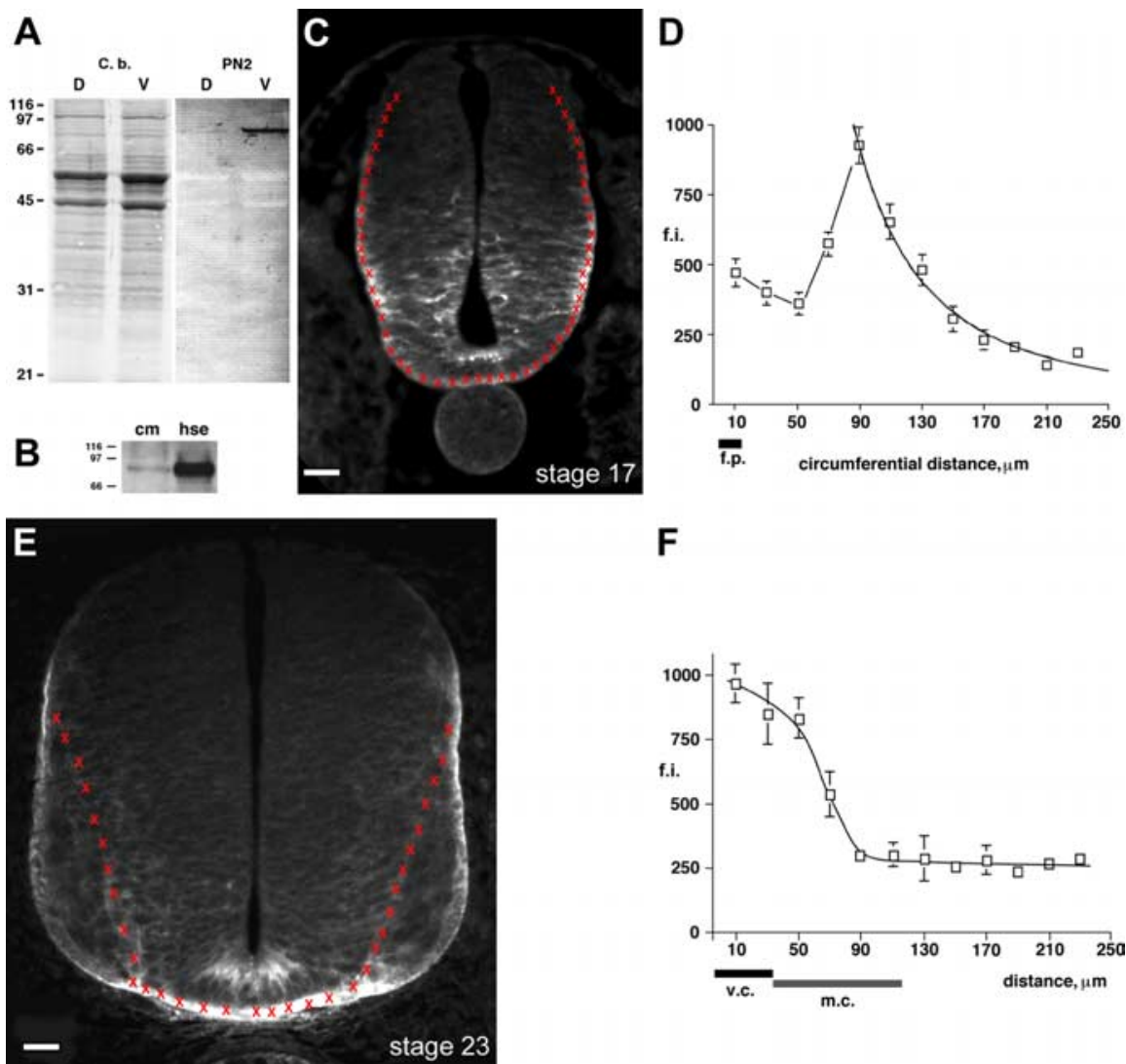

Figure 4. Graded distribution of netrin protein during commissural axon extension to the ventral midline of the embryonic chick spinal cord. $\boldsymbol{A}$, Western blot analysis indicates that netrin protein is enriched in the ventral portion of the stage 27 chick spinal cord. Stage 27 chick spinal cords were microdissected into dorsal (D) and ventral (V) halves and homogenized, and the protein content was quantified. Then $40 \mu \mathrm{g}$ of total protein was loaded per lane (indicated by equal Coomassie blue staining, C.b.). Antibody PN2 detects a band ( $\sim 78 \mathrm{kDa}$ ) that is present in the extract of dorsal spinal cord but is enriched in ventral protein extract. $\boldsymbol{B}$, Soluble netrin protein is detected in floor plate (f.p.) conditioned medium. Netrin immunoreactivity was detected in the conditioned media (cm) and the high salt extract (hse); PN2, $60 \mu \mathrm{g}$ of total protein per lane, separated by 10\% PAGE. Molecular weight markers are 116, 97, and $66 \mathrm{kDa}$. $\boldsymbol{C}-\boldsymbol{F}$, Quantification of netrin immunofluorescence in the stage 17 and stage 23 chick spinal cord (PN2). Red Xs mark the center of each area digitally sampled along the trajectory of extending commissural axons. Fluorescence was quantified by using a cooled CCD camera, a 1 s exposure, and a Cy3-conjugated secondary antibody. At stage 17 $(\boldsymbol{C})$ early commissural axons are extending circumferentially toward the floor plate. At stage $23(\boldsymbol{E})$ many axons have crossed the ventral midline; later-extending commissural axons travel directly through the expanding column of motor neurons (m.c.). Beginning at the ventral midline of the floor plate and proceeding along the trajectory of the extending commissural axons, we pooled data into 20 - $\mu \mathrm{m}$-long bins. Areas sampled were $6.92 \mu \mathrm{m}^{2}$, a total area of $\sim 48 \mu \mathrm{m}^{2}$. The red Xs mark the center of each $48 \mu \mathrm{m}^{2}$ data point. Scale bars: $\boldsymbol{C}, \boldsymbol{E}, 20 \mu \mathrm{m}$. Data were pooled from five stage 17 sections and three stage 23 sections, both left and right sides. In $\boldsymbol{D}$, the data from 90 to $250 \mu \mathrm{m}$ were best fit with a power function (CA Cricket Graph III). In $\boldsymbol{F}$, the data were best fit manually. Error bars are the SEM. Calculation of the steepness of the gradient illustrated in $\boldsymbol{D}$, discussed in Results, was performed as follows. The gradient was best fit with the following function: $\mathrm{FI}=7986690 \mathrm{D}^{-2.015}$. Based on the assumption that fixation shrinks the spinal cord to $60 \%$ of its normal size, a growth cone with a diameter of $25 \mu \mathrm{m}$ would shrink to $15 \mu \mathrm{m}$. Between 90 and $105 \mu \mathrm{m}(\boldsymbol{D})$, a $15 \mu \mathrm{m}$ distance at the high end of the gradient, the calculated corresponding fluorescence intensities (f.i.) are 922 and 676. If we assume that these are proportional to concentration, then $\Delta C=246$ and $\Delta C / C=27 \%$. Similarly, between 155 and $170 \mu \mathrm{m}, \Delta C=52$ and $\Delta C / C=17 \%$; between 235 and $250 \mu \mathrm{m}, \Delta C=15$ and $\Delta C / C=11 \%$. v.c., Ventral commissure.

1994), soluble netrin protein was detected in the conditioned medium, but the majority of netrin protein was present in the cell-associated high salt extract fraction (Fig. 4B).

\section{Quantification of the netrin gradient}

The immunohistochemical and biochemical analyses thus indicated that a graded distribution of netrin protein was present in the embryonic spinal neural epithelium. Fluorescent microscopy and digital image analysis were used to quantify the distribution of netrin immunofluorescence at stage 17 and stage 23 in chick brachial spinal cord. Images were captured by using a cooled CCD camera, and all images involved a $1 \mathrm{~s}$ exposure of Cy3 flu- orescence. In Figure 4 the red Xs mark the center of each area digitally sampled along the trajectory of extending commissural axons (Fig. 4C,E). Beginning at the ventral midline of the floor plate and proceeding circumferentially in both directions around the edge of the neural tube, data were pooled into $20-\mu \mathrm{m}$-long bins. Data from five stage 17 sections and three stage 23 sections, both left and right sides, were analyzed.

Quantification of netrin immunofluorescence at stage 17 revealed a graded increase in netrin protein for at least $150 \mu \mathrm{m}$ along the circumference of the neural tube directly in the path of extending commissural axons (Fig. 4C,D). However, in the ventralmost neuroepithelium immediately lateral to the floor plate, netrin immunoreactivity consistently decreased. This gap in the distribution of netrin protein immediately lateral to the floor plate was detected by using both pan-netrin antibodies (Figs. 2-5) and the netrin-1specific antibody (CN1) (Fig. 2B).

At stage 23 early extending commissural axons have crossed the ventral midline and have formed a thin ventral commissure. Quantitative analysis of immunofluorescence indicates that a graded increase in netrin protein continues to mark the trajectory of later-extending commissural axons that grow through the expanding pool of ventral horn motor neurons and that follow the earlier pioneers along the nascent ventral commissure to the midline (Fig. $4 E, F$ ).

All of the immunohistochemical analysis that has been described was performed by using tissue prepared with Carnoy's fixative, an organic dehydrating fix that causes significant shrinkage of the sample. Comparison of the embryos prepared for in situ hybridization via aqueous PFA fixation with embryos the same age processed by using Carnoy's fixative (Fig. 2) indicates that Carnoy's fixative shrinks the spinal cords to $\sim 60 \%$ their normal size in vivo. If we use $60 \%$ shrinkage as a correction factor, the gradients described would extend in vivo for at least $250 \mu \mathrm{m}$ at stage 17 and $150 \mu \mathrm{m}$ at stage 23 .

\section{Distribution of netrin-1 protein in the embryonic mouse and rat spinal cord}

In the absence of netrin- 1 function in the embryonic mouse spinal cord, the axons of commissural neurons initially grow along a normal trajectory in the dorsal spinal cord but then wander within the ventral neural epithelium, and many fail to extend appropriately toward the floor plate (Serafini et al., 1996). As the first commissural axons grow toward the ventral midline of the mouse spinal cord, netrin-1 is expressed at a high level by floor plate cells and at a lower level by cells in the ventral neural epi- 
thelium (Serafini et al., 1996). Thus the distribution of netrin-1 mRNA expression at these developmental stages in the mouse is similar to the sum of netrin-1 and netrin-2 in chick (Kennedy et al., 1994); indeed, no netrin-2 homolog appears to be present in the mouse genome, and netrin-1 in mouse appears to have taken over the functions of both netrin-1 and netrin-2 in chick. Antibody PN2 recognizes mouse netrin-1 and netrin-3; however, as the first commissural axons are extending toward the floor plate, netrin-3 mRNA is not expressed in the spinal cord (Wang et al., 1999), allowing us to use antibody PN2 to detect the distribution of netrin-1. PN2 reveals a graded distribution of netrin-1 protein in the E9.5 mouse spinal cord (Fig. $5 A, B$ ) similar to that seen with a pan-netrin antibody in stage 17 chick. Netrin protein is detected in the floor plate, throughout the ventral spinal cord, and in the path of extending commissural axons in the lateral neural epithelium. At E11.5 in the mouse (Fig. 5E,F), after many commissural axons have crossed the ventral midline, netrin immunoreactivity is still detected clearly in the apical floor plate. As in the chick, immunoreactivity is associated closely with the trajectory of commissural axons as they project through the expanding pool of ventral horn motor neurons, and concentrated in the ventral commissure.

Figure $5 C$ illustrates netrin immunoreactivity (PN2) in the E9.5 mouse spinal cord revealed by the use of an alkaline phosphatase-coupled secondary antibody and BM purple substrate. This image is presented at the same scale as the E11 rat spinal cord shown in Figure $5 D$. Figure $5, G$ and $H$, shows netrin immunoreactivity in the mouse E10.5 spinal cord and the rat E13 spinal cord revealed with antibody PN1, demonstrating that antibodies raised against different peptide antigens also identify the same distribution of netrin immunoreactivity in mouse and rat.

\section{Discussion}

\section{Graded distribution of netrin in the embryonic spinal cord}

The axons of the earliest born commissural interneurons grow circumferentially along the edge of the neural tube until they reach the ventral midline (Holley, 1982; Holley and Silver, 1987; Yaginuma et al., 1990, 1991). Here we report the presence of a graded distribution of netrin protein directly in the path of these axons as they grow through the neural epithelium toward the floor plate. Later-born commissural neurons extend axons that initially migrate ventrally along the edge of the neural tube but then change course at the dorsal edge of the enlarging pool of ventral horn motor neurons and grow ventromedially toward to the floor plate (Holley, 1982; Altman and Bayer, 1984; Wentworth, 1984; Yaginuma et al., 1991). Unlike the commissural pioneers, these axons will fasciculate with axons that previously have grown to the midline (Holley, 1982; Oppenheim et al., 1988). In addition to the gradient in the early neural tube, we also
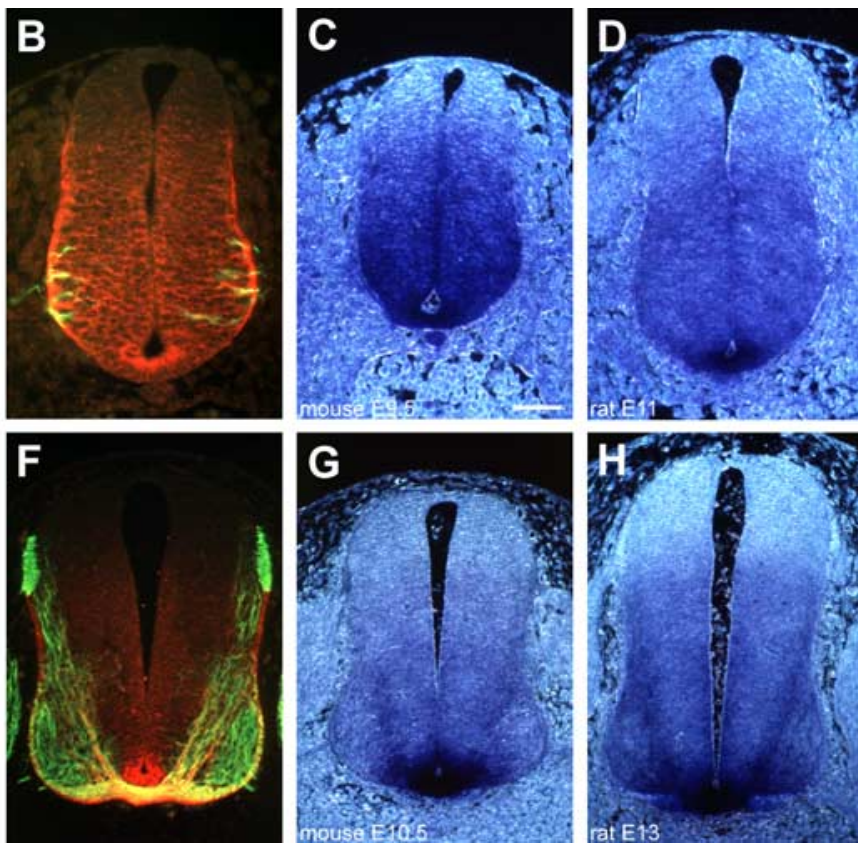

Figure 5. Distribution of netrin protein in the embryonic rat and mouse spinal cord. $\boldsymbol{A}, \boldsymbol{B}$, Netrin immunoreactivity (red) and photographed by using dark-field optics. All embryos were fixed with Carnoy's fixative, and all sections correspond to brachia ), $\boldsymbol{E}($ for $E-H), 50 \mu \mathrm{m}$

detect a graded distribution of netrin protein along the trajectory of these later-extending commissural axons.

\section{Netrin-1 as a long-range axon guidance cue}

As the first commissural neurons extend axons in the embryonic chick spinal cord, netrin-1 mRNA expression is restricted to the floor plate region, whereas netrin-1 protein is detected at least 20 neural epithelial cell diameters dorsal of the floor plate. This indicates that commissural axon growth cones likely first encounter netrin-1 protein at a significant distance from where the protein was secreted.

Unlike netrin-1, the distribution of netrin-2 protein is similar to the distribution of its mRNA. In situ hybridization analyses suggest that netrin-2 is expressed at a much lower level than netrin-1 (Kennedy et al., 1994; Wang et al., 1999). Previous experiments that used recombinant netrin-2 protein suggested that it was less diffusible than netrin-1 (Kennedy et al., 1994). Together with its low level of expression, this likely contributed to the restricted distribution of netrin-2 protein that was detected.

In mouse and rat the distribution of netrin immunoreactivity is very similar to that in the chick. Five netrin family members have been identified in mouse, and three are expressed in the embryonic spinal cord. Netrin-1 is expressed in the floor plate and ventral neural epithelium, a pattern similar to the sum of the distributions of netrin-1 and netrin-2 in chick. No ortholog of chick netrin-2 has been identified in mouse. Netrin-3 is expressed 
at a low level by motor neurons at E11.5 but has not been detected in the mouse spinal cord before E10.5 (Wang et al., 1999). Netrin$4 / \beta$-netrin is expressed by cells adjacent to the embryonic floor plate (Yin et al., 2000). Expression of the more distant relatives netrin-G1 and netrin-G2 has not been reported in the embryonic spinal cord (Nakashiba et al., 2000, 2002). It is unlikely that netrin-4, netrin-G1, or netrin-G2 was detected here, because the epitopes used to generate antibodies $\mathrm{PN} 1$ and $\mathrm{PN} 2$ are poorly conserved in these netrins. On this basis, the immunoreactivity revealed by PN1 and PN2 likely corresponds to netrin-1 in the E9.5 mouse spinal cord, with limited contribution of netrin-3 starting at E11.5. However, because netrin-1 is also expressed in the ventral two-thirds of the spinal cord in the mouse, we cannot determine how much of the gradient arises by diffusion from the midline as opposed to local production in that species.

\section{Long-range and short-range actions of netrins}

The contrast between netrin-1, detected at a distance from its site of expression in the chick spinal cord, and netrin-2, which is associated with the cells that express it, provides additional evidence for the possibility that netrins may act either at short or at long range, depending on context. Thus, whereas the evidence indicates that netrin-1 functions at long range in the spinal cord (Kennedy et al., 1994; Serafini et al., 1996), it acts at short range to guide retinal axons out of the eye into the optic nerve (Deiner et al., 1997). Similarly, evidence has been obtained for both shortand long-range actions of the netrin UNC- 6 in Caenorhabditis elegans (Adler et al., 2006; Wadsworth et al., 1996). The distance over which a netrin acts likely is determined by its extent of diffusion, which will depend, in turn, on the level of netrin expression as compared with the density of netrin binding sites on cell surfaces and ECM and on the sensitivity of the responding neuron. This recently has been well illustrated by Brankatschk and Dickson (2006), who showed that netrins at the Drosophila midline act at short range for commissural axon attraction but at long range in repelling other axons, presumably reflecting a greater sensitivity of the latter axons to a gradient.

\section{Gradient shape, slope, and length}

Baier and Bonhoeffer (1992) demonstrated that a gradient of tectal membranes could repel retinal ganglion cell axons and that the key factor determining axonal response was the slope of the gradient encountered by the growth cone. Assuming an average growth cone diameter of $25 \mu \mathrm{m}$, they found that the minimum concentration change (steepness) across the growth cone that could elicit a detectable response was 1-5\%. Goodhill and colleagues demonstrated an even greater sensitivity of sensory axons to gradients of NGF, at least at certain concentrations (Rosoff et al., 2004). Assuming the same average diameter and correcting for shrinkage caused by Carnoy's fixative, the stage 17 spinal cord gradient has an $11 \%$ change in concentration across a distance of $25 \mu \mathrm{m}$ at its low end that increases in steepness to a $27 \%$ change at its apex (Fig. 4), which we presume to be of more than sufficient steepness to be sensed by an advancing growth cone. Additionally, it has been argued that the maximum range over which a gradient of a target-derived diffusible factor could guide an axon is $\sim 1 \mathrm{~mm}$ (Goodhill, 1998). The $\sim 250 \mu \mathrm{m}$ graded distribution of netrin protein visualized in the stage 17 chick spinal cord and the $\sim 250 \mu \mathrm{m}$ range of the chemotropic axon-orienting activities of the floor plate (Placzek et al., 1990) or a cellular source of recombinant netrin (Kennedy et al., 1994) are all within this predicted range.

Curiously, the gradient of netrin protein present in the stage
17 brachial spinal cord does not extend to the edge of the floor plate. Instead, a gap immediately lateral to the floor plate containing little netrin protein has been found consistently. At least two possibilities may account for this. First, as netrin diffuses away from the floor plate, it likely becomes associated with cell membranes or ECM. Fixation may capture only the bound netrin, not the unbound soluble fraction. If so, the gap in immunoreactivity next to the floor plate could reflect a reduced matrixbinding capacity in that region, although unbound netrin emanating from the floor plate, not detected immunohistochemically, nonetheless would be present. A second possibility is that netrin protein is secreted by floor plate cells but then is captured mainly on the surface of proliferating neural epithelial cells. In this case a combination of secretion, diffusion, capture, and redistribution, e.g., via cell and axon migration, conceivably could result in the distribution that has been observed. This second mechanism is perhaps less plausible because special conditions would need to apply to these processes, particularly the redistribution processes, for a gap in immunoreactivity to appear where it does. Both explanations postulate the existence of netrin-binding sites in the spinal cord, the identity and distribution of which remain to be investigated in additional detail.

In the second case, in which the gap reflects an absence of netrin, we would have to assume that netrin-1 guides commissural axons circumferentially into the ventral spinal cord but does not lead them over the final stretch to the ipsilateral edge of the floor plate. Other mechanisms, including a presumed gradient of Shh (Charron et al., 2003), therefore would be responsible for guiding them across the gap. In the first case, in which a gradient of soluble netrin is present in the gap region, a combination of netrin and other cues like Shh would be responsible for guidance in this region. It is interesting to speculate that a gradient of soluble netrin in fact might be sharper and more effective at guiding the axons across the gap than a gradient of bound netrin, a possibility that requires additional theoretical and experimental exploration. In either model, once the axons reach the proximal edge of the floor plate, the engagement of local short-range cues would guide the axons into the ventral commissure (Stoeckli and Landmesser, 1995; Stoeckli et al., 1997; Burstyn-Cohen et al., 1999).

Although gradients long have been proposed to guide axon growth during neural development, limited numbers of graded distributions of axon guidance cues have been reported (Braisted et al., 1997; Monschau et al., 1997; Isbister et al., 1999; Lyuksyutova et al., 2003; Bourikas et al., 2005), and in no instance has a gradient of a secreted long-range axon guidance protein diffusing away from its site of synthesis been visualized in vivo. Our observation of a graded distribution of netrin immunoreactivity in the neuroepithelium of the embryonic chick spinal cord, extending many cell diameters from its source in the floor plate and placed directly in the path of extending commissural axons, supports the operation of long-range diffusible chemoattractive cues in axon guidance.

\section{References}

Adler CE, Fetter RD, Bargmann CI (2006) UNC-6/netrin induces neuronal asymmetry and defines the site of axon formation. Nat Neurosci 9:511-518.

Altman J, Bayer SA (1984) The development of the rat spinal cord. Adv Anat Embryol Cell Biol 85:1-164.

Baier H, Bonhoeffer F (1992) Axon guidance by gradients of a targetderived component. Science 255:472-475.

Bourikas D, Pekarik V, Baeriswyl T, Grunditz A, Sadhu R, Nardo M, Stoeckli 
ET (2005) Sonic hedgehog guides commissural axons along the longitudinal axis of the spinal cord. Nat Neurosci 8:297-304.

Braisted JE, McLaughlin T, Wang HU, Friedman GC, Anderson DJ, O’Leary DD (1997) Graded and lamina-specific distributions of ligands of EphB receptor tyrosine kinases in the developing retinotectal system. Dev Biol 191:14-28.

Brankatschk M, Dickson BJ (2006) Netrins guide Drosophila commissural axons at short range. Nat Neurosci 9:188-194.

Burstyn-Cohen T, Tzarfaty V, Frumkin A, Feinstein Y, Stoeckli E, Klar A (1999) F-spondin is required for accurate pathfinding of commissural axons at the floor plate. Neuron 23:233-246.

Charron F, Stein E, Jeong J, McMahon AP, Tessier-Lavigne M (2003) The morphogen Sonic hedgehog is an axonal chemoattractant that collaborates with netrin-1 in midline axon guidance. Cell 113:11-23.

Deiner MS, Kennedy TE, Fazeli A, Serafini T, Tessier-Lavigne M, Sretavan DW (1997) Netrin-1 and DCC mediate axon guidance locally at the optic disc: loss of function leads to optic nerve hypoplasia. Neuron 19:575-589.

Dickson BJ (2002) Molecular mechanisms of axon guidance. Science 298:1959-1964.

Goodhill GJ (1998) Mathematical guidance for axons. Trends Neurosci $21: 226-231$.

Hamburger V, Hamilton HL (1992) A series of normal stages in the development of the chick embryo: 1951. Dev Dyn 195:231-272.

Harlow E, Lane D (1988) Antibodies: a laboratory manual. Cold Spring Harbor, NY: Cold Spring Harbor Laboratory.

Holley JA (1982) Early development of the circumferential axonal pathway in mouse and chick spinal cord. J Comp Neurol 205:371-382.

Holley JA, Silver J (1987) Growth pattern of pioneering chick spinal cord axons. Dev Biol 123:375-388.

Isbister CM, Tsai A, Wong ST, Kolodkin AL, O’Connor TP (1999) Discrete roles for secreted and transmembrane semaphorins in neuronal growth cone guidance in vivo. Development 126:2007-2019.

Kennedy TE, Serafini T, de la Torre JR, Tessier-Lavigne M (1994) Netrins are diffusible chemotropic factors for commissural axons in the embryonic spinal cord. Cell 78:425-435.

Koch M, Murrell JR, Hunter DD, Olson PF, Jin W, Keene DR, Brunken WJ, Burgeson RE (2000) A novel member of the netrin family, $\beta$-netrin, shares homology with the $\beta$ chain of laminin: identification, expression, and functional characterization. J Cell Biol 151:221-234.

Lee VM, Carden MJ, Schlaepfer WW, Trojanowski JQ (1987) Monoclonal antibodies distinguish several differentially phosphorylated states of the two largest rat neurofilament subunits (NF-H and NF-M) and demonstrate their existence in the normal nervous system of adult rats. J Neurosci 7:3474-3488.

Lyuksyutova AI, Lu CC, Milanesio N, King LA, Guo N, Wang Y, Nathans J, Tessier-Lavigne M, Zou Y (2003) Anterior-posterior guidance of commissural axons by Wnt-frizzled signaling. Science 302:1984-1988.

MacLennan AJ, McLaurin DL, Marks L, Vinson EN, Pfeifer M, Szulc SV, Heaton MB, Lee N (1997) Immunohistochemical localization of netrin-1 in the embryonic chick nervous system. J Neurosci 17:5466-5479.

Manitt C, Colicos MA, Thompson KM, Rousselle E, Peterson AC, Kennedy TE (2001) Widespread expression of netrin-1 by neurons and oligodendrocytes in the adult mammalian spinal cord. J Neurosci 21:3911-3922.

McLaughlin T, Hindges R, O'Leary DD (2003) Regulation of axial patterning of the retina and its topographic mapping in the brain. Curr Opin Neurobiol 13:57-69.

Monschau B, Kremoser C, Ohta K, Tanaka H, Kaneko T, Yamada T, Handwerker C, Hornberger MR, Loschinger J, Pasquale EB, Siever DA, Verderame MF, Muller BK, Bonhoeffer F, Drescher U (1997) Shared and distinct functions of RAGS and ELF-1 in guiding retinal axons. EMBO J $16: 1258-1267$.

Nakashiba T, Ikeda T, Nishimura S, Tashiro K, Honjo T, Culotti JG, Itohara
S (2000) Netrin-G1: a novel glycosyl phosphatidylinositol-linked mammalian netrin that is functionally divergent from classical netrins. J Neurosci 20:6540-6550.

Nakashiba T, Nishimura S, Ikeda T, Itohara S (2002) Complementary expression and neurite outgrowth activity of netrin-G subfamily members. Mech Dev 111:47-60.

Oppenheim RW, Shneiderman A, Shimizu I, Yaginuma H (1988) Onset and development of intersegmental projections in the chick embryo spinal cord. J Comp Neurol 275:159-180.

Placzek M, Tessier-Lavigne M, Jessell T, Dodd J (1990) Orientation of commissural axons in vitro in response to a floor plate-derived chemoattractant. Development 110:19-30.

Ramón y Cajal S (1892) La rétine des vertèbres. Cellule 9:121-255.

Ramón y Cajal S (1899) Textura del sistema nervioso del hombre y de los vertebrados: estudios sobre el plan estructural y composición histológica de los centros nerviosos adicionados de consideraciones fisiológicas fundadas en los nuevos descubrimientos. Madrid: Moya.

Rosoff WJ, Urbach JS, Esrick MA, McAllister RG, Richards LJ, Goodhill GJ (2004) A new chemotaxis assay shows the extreme sensitivity of axons to molecular gradients. Nat Neurosci 7:678-682.

Serafini T, Kennedy TE, Galko MJ, Mirzayan C, Jessell TM, Tessier-Lavigne M (1994) The netrins define a family of axon outgrowth-promoting proteins homologous to C. elegans UNC-6. Cell 78:409-424.

Serafini T, Colamarino SA, Leonardo ED, Wang H, Beddington R, Skarnes WC, Tessier-Lavigne M (1996) Netrin-1 is required for commissural axon guidance in the developing vertebrate nervous system. Cell 87:1001-1014.

Shi SR, Key ME, Kalra KL (1991) Antigen retrieval in formalin-fixed, paraffin-embedded tissues: an enhancement method for immunohistochemical staining based on microwave oven heating of tissue sections. J Histochem Cytochem 39:741-748.

Stoeckli ET, Landmesser LT (1995) Axonin-1, Nr-CAM, and Ng-CAM play different roles in the in vivo guidance of chick commissural neurons. Neuron 14:1165-1179.

Stoeckli ET, Sonderegger P, Pollerberg GE, Landmesser LT (1997) Interference with axonin-1 and Nr-CAM interactions unmasks a floor plate activity inhibitory for commissural axons. Neuron 18:209-221.

Swedlow JR, Sedat JW, Agard DA (1993) Multiple chromosomal populations of topoisomerase II detected in vivo by time-lapse, threedimensional wide-field microscopy. Cell 73:97-108.

Tessier-Lavigne M, Placzek M, Lumsden AG, Dodd J, Jessell TM (1988) Chemotropic guidance of developing axons in the mammalian central nervous system. Nature 336:775-778.

Wadsworth WG, Bhatt H, Hedgecock EM (1996) Neuroglia and pioneer neurons express UNC-6 to provide global and local netrin cues for guiding migrations in C. elegans. Neuron 16:35-46.

Wang H, Copeland NG, Gilbert DJ, Jenkins NA, Tessier-Lavigne M (1999) Netrin-3, a mouse homolog of human NTN2L, is highly expressed in sensory ganglia and shows differential binding to netrin receptors. J Neurosci 19:4938-4947.

Wentworth LE (1984) The development of the cervical spinal cord of the mouse embryo. II. A Golgi analysis of sensory, commissural, and association cell differentiation. J Comp Neurol 222:96-115.

Yaginuma H, Shiga T, Homma S, Ishihara R, Oppenheim RW (1990) Identification of early developing axon projections from spinal interneurons in the chick embryo with a neuron-specific $\beta$-tubulin antibody: evidence for a new "pioneer" pathway in the spinal cord. Development 108:705-716.

Yaginuma H, Homma S, Kunzi R, Oppenheim RW (1991) Pathfinding by growth cones of commissural interneurons in the chick embryo spinal cord: a light and electron microscopic study. J Comp Neurol 304:78-102.

Yin Y, Sanes JR, Miner JH (2000) Identification and expression of mouse netrin-4. Mech Dev 96:115-119. 